\title{
THE TRIAD SYSTEMS OF THIRTEEN LETTERS*
}

F. N. COLE

Distributions of thirteen letters in triads were given by Kirkman, $\nmid$ Reiss, $\ddagger$ Netto, $\&$ and De Vries.\| In his doctor dissertation Zulauf 9 reduced the known systems to two, those of Kirkman, Reiss, and De Vries being equivalent and having an intransitive group of order 6 , while that of Netto has a transitive group of order 39. Exhaustive enumerations by De Pasquale ** and Brunel $\dagger \dagger$ have shown that the two distributions mentioned are the only possible ones for thirteen letters, apart from mere variations in notation.

The investigations of De Pasquale and Brunel are based on the Kantor configurations $(3,3)_{10}$, to which the triad systems in thirteen letters reduce on the suppression of those triads which contain any one of the three letters of a selected triad. While this method leaves little to be desired in point of efficiency, it is quite possible to obtain the systems by the theory of substitutions alone, as is accomplished in the present paper.

A guiding principle here employed is that of "interlacing," the nature of which is sufficiently indicated by the instance $x a b, x c d ; y a c, y b d$. It may be permitted to speak of this distribution as an interlacing of $x$ and $y$. From elementary considerations it is plain that such interlacing is unavoidable in the triad system of seven letters, but is excluded in the case of nine letters. For thirteen letters it is again unavoidable. The proof is sufficiently tedious, but straightforward.

1. Thus, excluding interlacing and disregarding mere matters of notation, we may begin the table of triads with

* Presented to the Society, September 11,1912.

† Theorems on combinations, C a mbridge and Dublin Mat hematical Journ a l, vol. 8 (1853).

¥Ueber eine Steinersche kombinatorische Aufgabe, Crell e's J o u r n a l, vol. 56 (1859).

8 Zur Theorie der Tripelsysteme, Mathe matische Annalen, vol. 42 (1892).

$\|$ Zur Theorie der Tripelsysteme, Rendiconti del Circolo Matematico di Palermo, vol. 8 (1894).

II Ueber Tripelsysteme von 19 Elementen, Marburg, 1897.

** Sui sistemi ternari di 18 elementi, Rendic onti R. Istit u to L ombardo, ser. 2, vol. 32 (1899).

t† Sur les deux systemes de triades de treize elements, Journal de Mat hématiques, ser. 5 , vol. 7 (1901).

Trans. Amer. Math. Soc. 1 


\begin{tabular}{|c|c|c|c|c|}
\hline 123 & 145 & 167 & $\begin{array}{lll}18 & 9\end{array}$ & 11011 \\
\hline & 246 & 258 & 2710 & $\begin{array}{lll}2 & 9 & 12\end{array}$ \\
\hline
\end{tabular}

The system thus far developed is unaltered by the dihedral group of order 20: $G=\{(12)(3)(49116813751210),(12)(3)(4)(56)(78)(910)$ (11 12) (13) \}.

Continuing the formation of the system by taking the pair 43 with a third letter, we find three possibilities not equivalent under $G$, viz., 439,4311 , 4313 . The table below shows the continuation of the building process. In each division any one of the rows on the right may be combined with any row on the left.

\begin{tabular}{|c|c|c|c|c|c|c|}
\hline 4711 & 4813 & 41012 & 913 & 10 & 95 & 9116 \\
\hline 4712 & 4811 & 41013 & 913 & 6 & $\begin{array}{lll}9 & 5 & 10\end{array}$ & 9117 \\
\hline 4713 & 4810 & 41112 & 913 & 7 & $\begin{array}{lll}9 & 5 & 11\end{array}$ & 9106 \\
\hline 4713 & 4811 & 41012 & 913 & 7 & $\begin{array}{lll}9 & 5 & 10\end{array}$ & $\begin{array}{lll}9 & 116\end{array}$ \\
\hline
\end{tabular}

II. 43 11. Invariant under (1 2) (4 11) (5 13) (6 10) (8 12).

\begin{tabular}{|c|c|c|c|c|c|c|}
\hline 47 & $\begin{array}{lll}49 & 13\end{array}$ & $\begin{array}{lll}4 & 10 & 12\end{array}$ & 117 & & 11 & 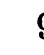 \\
\hline $\begin{array}{lll}47 & 9\end{array}$ & 4812 & 41013 & 117 & 9 & 11 & \\
\hline 13 & 4812 & $\begin{array}{lll}4 & 9 & 10\end{array}$ & 117 & 8 & 11 & 12 \\
\hline 713 & 4812 & $\begin{array}{lll}4 & 9 & 10\end{array}$ & 115 & 7 & 11 & \\
\hline
\end{tabular}

III. 43 13. Invariant under (4 13) (5 12) (6 11) (7 10) (8 9).

\begin{tabular}{|c|c|c|c|c|c|}
\hline 47 & 4910 & 41112 & 13109 & 1378 & 1356 \\
\hline 47 & $\begin{array}{lll}4 & 9 & 11\end{array}$ & 41012 & 13109 & 1368 & 1375 \\
\hline $\begin{array}{lll}47 & 9\end{array}$ & 4810 & $\begin{array}{lll}411 & 12\end{array}$ & 13108 & 1397 & 1356 \\
\hline 4711 & $\begin{array}{lll}4812\end{array}$ & $\begin{array}{lll}4 & 9 & 10\end{array}$ & 13106 & 1359 & 138 \\
\hline
\end{tabular}

In every one of these cases there is conflict in the formation of the triads, e. g., 4713 and 9137 , or interlacing, or these conditions arise as soon as one attempts to extend the formation further.

2. Interlacing being therefore indispensable, we find again a single representative opening for the table:

\begin{tabular}{|c|c|c|c|c|c|}
\hline 123 & 145 & 167 & $\begin{array}{lll}18 & 9\end{array}$ & 11011 & 11213 \\
\hline & 46 & 257 & 2810 & $\begin{array}{lll}2 & 9 & 12\end{array}$ & $\begin{array}{lll}2 & 11\end{array}$ \\
\hline
\end{tabular}

This is unchanged by the group of order $48: G=\left\{\left(\begin{array}{ll}45 \\ 4\end{array}\right)\left(\begin{array}{l}6 \\ 7\end{array}\right),\left(\begin{array}{ll}46 \\ 6\end{array}\right)(57)\right.$, (4 7) (5 6); (8 11 12) (9 1013 ), (8 9) (10 12) (11 13); (1 2) (4 576 ) (8 912131110$)\}$.

Two cases now arise: 473 and 478 . The former is invariant under (4 7 ) (5 6). Its continuations are 


\begin{tabular}{|c|c|c|c|c|c|}
\hline $\begin{array}{lll}48 & 11\end{array}$ & 4913 & 41012 & 7811 & $\begin{array}{lll}7 & 9 & 13\end{array}$ & 71012 \\
\hline 12 & $\begin{array}{lll}49 & 11\end{array}$ & 41013 & 7812 & $\begin{array}{lll}7 & 9 & 11\end{array}$ & 7101 \\
\hline & 4910 & 41112 & 7813 & 7910 & 711 \\
\hline & 4911 & 41012 & 7813 & $\begin{array}{lll}7 & 9 & 11\end{array}$ & 7 \\
\hline
\end{tabular}

where again any row on the right goes with any row on the left.

The first three rows are equivalent under the substitution (8 11 12) (9 1013 ), and the last row on the left is incompatible with any row on the right. There remain then only two possibilities

\begin{tabular}{|c|c|c|c|}
\hline 11 & 4913 & 41012 & $\begin{array}{lll}7 & 8 & 12 \\
7 & 8 & 13\end{array}$ \\
\hline
\end{tabular}

and these are equivalent (8 9) (10 12) (11 13). Further triads must now be formed from 8 with $3,5,6,13$ and from 13 with $3,5,6,8$, an obvious conflict. The case 473 is therefore to be rejected.

3. The case 478 is invariant under ( $\left.\begin{array}{ll}1 & 2\end{array}\right)\left(\begin{array}{ll}5 & 6\end{array}\right)\left(\begin{array}{l}9 \\ 10\end{array}\right)$ (11 12). There are three subcases 439,4311 , and 4313 , and these lead to

\begin{tabular}{|c|c|c|c|c|c|c|c|}
\hline 439 & & 013 & $\begin{array}{lll}411 & 12\end{array}$ & 7311 & 7 & $\begin{array}{ll}9 & 13\end{array}$ & $\begin{array}{lll}7 & 10 & 12\end{array}$ \\
\hline & & & & 7313 & 7 & 911 & $\begin{array}{lll}7 & 10 & 12\end{array}$ \\
\hline 4311 & 4 & 913 & 41012 & $\begin{array}{lll}73 & 9\end{array}$ & 7 & 1013 & 71112 \\
\hline & & & & 7312 & 7 & 911 & $\begin{array}{lll}7 & 10 & 13\end{array}$ \\
\hline & & & & 7313 & 7 & 910 & $\begin{array}{lll}711 & 12\end{array}$ \\
\hline 4313 & 4 & 910 & 41112 & 7311 & 7 & 913 & $\begin{array}{lll}7 & 10 & 12\end{array}$ \\
\hline & & & & 7312 & 7 & 911 & $\begin{array}{lll}7 & 10 & 13\end{array}$ \\
\hline 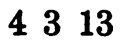 & 4 & 911 & 41012 & $\begin{array}{lll}7 & 3 & 9\end{array}$ & 7 & 1013 & $\begin{array}{lll}711 & 12\end{array}$ \\
\hline & & & & 7310 & 7 & 913 & $\begin{array}{lll}711 & 12\end{array}$ \\
\hline
\end{tabular}

Here $a$ and $c, b$ and $h, e$ and $f$ are equivalent under (4 7) (5 6); $f$ and $g, h$ and $i$ are equivalent under (1 2) (5 6) (9 10) (11 12). Further, $a$

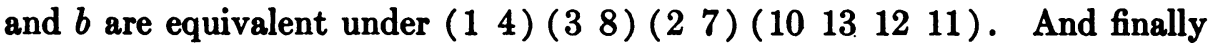
$d$ requires triads to be formed from 9 with $3,5,6,10$ and 10 with $3,5,6,9$.

There survive only two distinct cases:

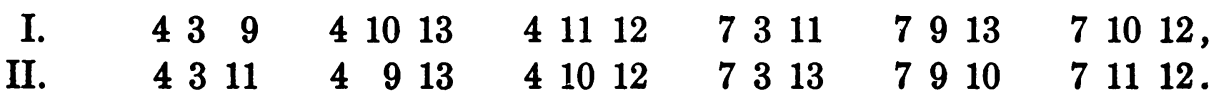

Case II is continued by 1238,1256 , and either of the following:

$\begin{array}{llllllllllll}1158 & 1169 & 935 & 1036 & 10513 & 136 & 8 \text {, } \\ 1168 & & 1159 & 936 & 1035 & 106 & 13 & 1358 & \end{array}$

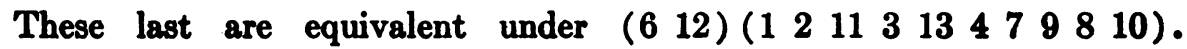


The complete triad system for Case II is then:

\begin{tabular}{|c|c|c|c|c|c|c|c|}
\hline $\begin{array}{lll}12 & 3\end{array}$ & 145 & 16 & 189 & & 1011 & & 1213 \\
\hline 21 & 246 & 25 & 2810 & 2 & 912 & 2 & 1113 \\
\hline 31 & 3411 & $\begin{array}{lll}3 & 5 & 9\end{array}$ & 3610 & 3 & 713 & 3 & 812 \\
\hline 41 & 426 & 4311 & 478 & 4 & $\begin{array}{ll}9 & 13\end{array}$ & 4 & 1012 \\
\hline 51 & 52 & $\begin{array}{lll}5 & 3 & 9\end{array}$ & 5612 & 5 & 811 & 5 & 1013 \\
\hline $\begin{array}{lll}6 & 1 & 7\end{array}$ & 62 & 6310 & 6512 & 6 & 813 & 6 & 911 \\
\hline $\begin{array}{lll}7 & 1 & 6\end{array}$ & 725 & 7313 & 748 & 7 & 910 & 7 & 1112 \\
\hline $\begin{array}{lll}8 & 1 & 9\end{array}$ & 8210 & 8312 & 847 & 8 & 511 & 8 & 613 \\
\hline $\begin{array}{lll}9 & 1 & 8\end{array}$ & 9212 & 93 & 9413 & 9 & 611 & 9 & 710 \\
\hline 10111 & 1028 & 103 & 10412 & 10 & 513 & 10 & \\
\hline 11110 & 11213 & 113 & $\begin{array}{lll}11 & 5 & 8\end{array}$ & 11 & 69 & 11 & 712 \\
\hline 12113 & 1229 & 123 & 12410 & 12 & 56 & 12 & \\
\hline 13112 & 13211 & 1337 & 1349 & 13 & 510 & 13 & 6 \\
\hline
\end{tabular}

Here the interlacing is as follows:

1 with $2,9,10,12$; 2 with $1,5,8,9$; 3 with $7,9,10$; 4 with $7,11,12,13$; 5 with $2,6,7,12$; 6 with $5,10,13$;

7 with $3,4,5,11 ; 8$ with $2,11,13$; 9 with $1,2,3,13$; 10 with $1,3,6,11 ; 11$ with $4,7,8,10 ; 12$ with $1,4,5$; 13 with $, 6,8,9$.

The group which leaves the triad system unchanged is therefore intransitive and does not connect $1,2,4,5,7,9,10,11,13$ and $3,6,8,12$. It con-

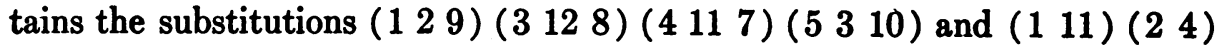
( 513 ) ( 79 9) ( 8 12), but not any substitution $\left(\begin{array}{lll}3 & 6 & 8\end{array}\right) \cdots$ nor any that leaves $3,8,12$ each fixed. It follows that the group is of order 6 and is that generated by the two substitutions above. The systems of transitivity are $1,2,4,7,9,11 ; 3,8,12 ; 5,10,1 \delta ; 6$.

4. Case I leads to

$\begin{array}{llllllllll}9510 & 9611 & 1036 & 1158 & 6512 & 6813 & 5313 & 8312 & a \\ & & & & 6513 & 6812 & 5312 & 8313 & b \\ 9511 & 9610 & 1035 & 1168 & 6512 & 6313 & 5813 & 8312 & c \\ & & & & 6513 & 6312 & 5812 & 8313 & d\end{array}$

Of these $b, c, d$ are equivalent to Case II under ( $\left.\begin{array}{lll}1 & 5 & 2\end{array} 6\right)$ (4 7 ) ( 3129

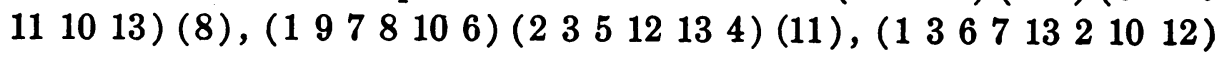
(84911) (5), respectively. There remains only $a$, which leads to the triad system 


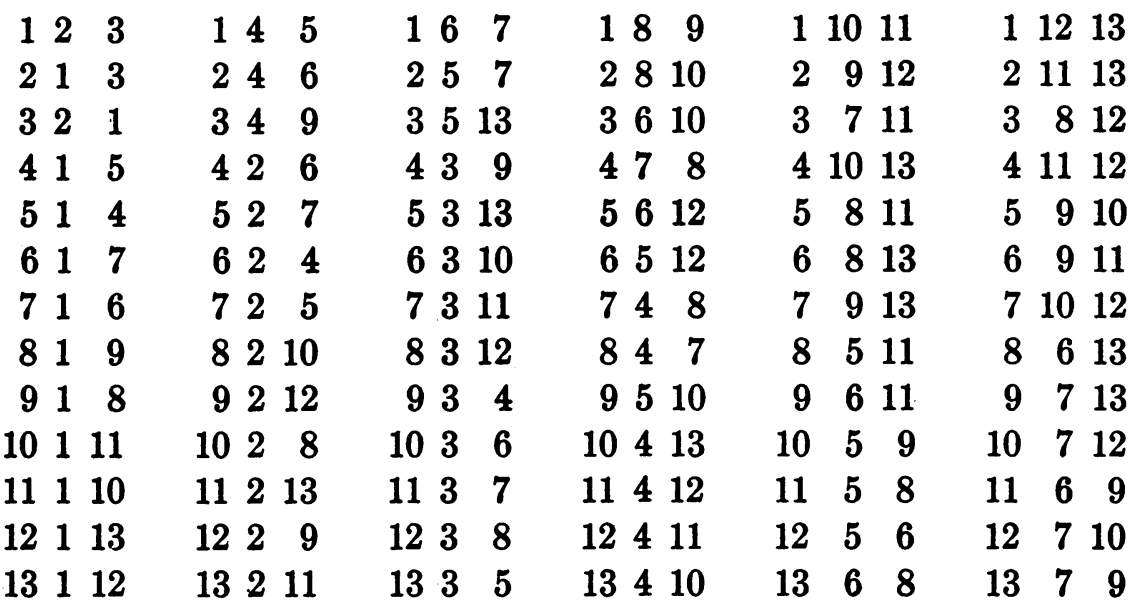

The interlacing is as follows:

1 with $2,3,4,5,12,13$;

5 with $1,4,6,8,11,12$;

2 with 1, 3, 8, 10, 11, 13; 6 with $3,5,9,10,11,12$;

3 with 1, 2, 4, 6, 9, 10; 7 with $4,8,9,10,12,13$; 4 with $1,3,5,7,8,9$; 8 with $2,4,5,7,10,11$;

9 with $3,4,6,7,11,13$;

10 with $2,3,6,7,8,12$;

11 with $2,5,6,8,9,13$;

12 with $1,5,6,7,10,13$;

13 with $1,2,7,9,11,12$.

The system is invariant under the substitutions

(12843107961213115) and (24 12) (35 13) (8 710 ) (6 11 9).

It is readily found that no substitution with two fixed letters leaves the system invariant. The order of its group is therefore a divisor of 13.12, and it is metacyclic. In fact its order is 39.

Columara Universitr. 